\title{
Negative feedback regulation of the ERK1/2 MAPK pathway
}

\author{
David Lake $^{1}$ Sonia A. L. Corrêa ${ }^{2,3}$ (I) Jürgen Müller ${ }^{1,4}$
}

Received: 3 February 2016/Revised: 16 June 2016/Accepted: 17 June 2016/Published online: 24 June 2016

(c) The Author(s) 2016. This article is published with open access at Springerlink.com

\begin{abstract}
The extracellular signal-regulated kinase $1 / 2$ (ERK1/2) mitogen-activated protein kinase (MAPK) signalling pathway regulates many cellular functions, including proliferation, differentiation, and transformation. To reliably convert external stimuli into specific cellular responses and to adapt to environmental circumstances, the pathway must be integrated into the overall signalling activity of the cell. Multiple mechanisms have evolved to perform this role. In this review, we will focus on negative feedback mechanisms and examine how they shape ERK1/ 2 MAPK signalling. We will first discuss the extensive number of negative feedback loops targeting the different components of the ERK1/2 MAPK cascade, specifically the direct posttranslational modification of pathway components by downstream protein kinases and the induction of de novo gene synthesis of specific pathway inhibitors. We will then evaluate how negative feedback modulates the spatiotemporal signalling dynamics of the ERK1/2 pathway regarding signalling amplitude and duration as well as subcellular localisation. Aberrant ERK1/2 activation results in deregulated proliferation and malignant transformation in model systems and is commonly observed in human tumours. Inhibition of the ERK1/2
\end{abstract}

Jürgen Müller

j.muller2@aston.ac.uk

1 Warwick Medical School, University of Warwick, Coventry, UK

2 School of Life Sciences, University of Warwick, Coventry, UK

3 Faculty of Life Sciences, University of Bradford, Bradford, UK

4 Aston Medical Research Institute, Aston Medical School, Aston University, Birmingham B4 7ET, UK pathway thus represents an attractive target for the treatment of malignant tumours with increased ERK1/2 activity. We will, therefore, discuss the effect of ERK1/2 MAPK feedback regulation on cancer treatment and how it contributes to reduced clinical efficacy of therapeutic agents and the development of drug resistance.

Keywords Cell signalling - Negative feedback · Signalling dynamics - Spatiotemporal regulation . Pathway modelling - Cancer

\section{Introduction}

\section{The ERK1/2 MAPK pathway}

Eukaryotic cells respond to changes in their environment through complex and interconnected signal transduction networks that convert external stimuli into a range of cellular responses. A common motif by which extracellular modulation of cell-surface receptor activity is transduced into a specific cellular response is the three-tiered mitogenactivated protein kinase (MAPK) cascade, with the extracellular signal-regulated kinase 1/2 (ERK1/2) pathway being the most extensively investigated. The principal mechanisms involved in the activation of the ERK1/2 pathway have been well characterised [1]. In brief, signalling is initiated when an extracellular ligand binds to a specific receptor tyrosine kinase (RTK) at the plasma membrane. This promotes receptor dimerisation and autophosphorylation on intracellular tyrosine residues that then act as recognition sites for proteins containing $\mathrm{Src}$ homology 2 (SH2) or phosphotyrosine binding (PTB) domains, including the adaptor proteins Shc and Grb2. Son of sevenless (SOS) is then recruited from the cytosol to the 
plasma membrane through Shc and Grb2 and acts as the major guanine nucleotide exchange factor (GEF) that catalyses the conversion of inactive Ras-GDP to active Ras-GTP [2]. Activated Ras-GTP then recruits Raf to the plasma membrane, where it is activated in a complex fashion (for review, see [3, 4]). Once activated, all Raf family members (A-Raf, B-Raf, and c-Raf (Raf-1) [5]) are capable of activating $\mathrm{MEK} 1 / 2$, which in turn activates ERK1/2. This is achieved by phosphorylation in the activation segment of their respective kinase domains. The ultimate outcome is the phosphorylation of a large variety of critical targets by ERK1/2. Over 150 ERK1/2 substrates, including many nuclear transcription factors, have been identified [6]. The specific set of targets that are phosphorylated under particular extra- and intracellular conditions determines the appropriate response of the cell.

\section{Regulation of the ERK1/2 signalling pathway}

To adapt to particular environmental circumstances, the ERK1/2 MAPK pathway must be integrated into the overall signalling activity of the cell. Importantly, the magnitude, duration, and location of MAPK signalling must be strictly controlled to produce the correct biological response. Multiple mechanisms have evolved to perform this role, including positive and negative feedback loops as well as extensive cross talk between parallel pathways. In this review, we will focus on negative feedback and the mechanisms by which it shapes ERK1/2 MAPK signalling. Negative feedback loops targeting the ERK1/2 MAPK cascade fall into two main categories: direct posttranslational modification of pathway components and the induction of de novo gene synthesis of specific pathway inhibitors. The principal difference between these two mechanisms is the time required to take effect. While direct posttranslational modification is nearly instantaneous, de novo gene expression and protein synthesis is somewhat delayed following the initial pathway activation. In this review, we will discuss in detail how negative feedback determines ERK1/2 spatiotemporal signalling dynamics and the role of negative feedback regulation in the development and treatment of cancer.

\section{Inhibitory feedback phosphorylation by downstream kinases}

Nearly all components of the ERK1/2 MAPK cascade are regulated through negative feedback phosphorylation by downstream kinases. The negative feedback phosphorylation events that have been studied in reasonable detail are summarised in Table 1 and Fig. 1 and will be further discussed in this article.

\section{Growth factor receptors}

ERK1/2 proteins have been reported to directly phosphorylate several receptor tyrosine kinases. For example, ERK1/2 MAPKs can phosphorylate the epidermal growth factor (EGF) receptor (EGFR) at T669 [7, 8], the major site of Ser/Thr phosphorylation of the receptor. Phosphorylation on this conserved residue, which is located in the juxtamembrane region of the receptor, was shown to be induced by tumour necrosis factor (TNF)- $\alpha$, EGF, or heregulin (HRG) in a breast cancer cell line [9]. T669 phosphorylation was dependent on ERK1/2 activity and was subsequently shown to reduce the level of constitutive EGFR tyrosine phosphorylation, suggesting that it could downregulate EGFR signalling. The mechanism involved appears to be a reduced ability of the phosphorylated juxtamembrane region to cross activate the other receptor kinase of the dimer, even across heterodimeric receptors [9]. ERBB3 (erb-b2 receptor tyrosine kinase 3) has been shown to be phosphorylated in a position similar to T669 of the EGFR, leading to reduced tyrosine phosphorylation of the receptor [10], likely through a similar mechanism. Interestingly, another report demonstrated that while EGFstimulated, ERK1/2-dependent phosphorylation of T669 reduced tyrosine phosphorylation and the activity of the EGF receptor, T669 phosphorylation also inhibited receptor downregulation, thereby acting as a positive regulator of signalling [11]. It is, therefore, possible that the same phosphorylation event controls both the duration of the initial signal as well as the subsequent internalisation of the receptor. An attractive hypothesis is that the negative regulation of EGFR activity by T669 phosphorylation is the event that causes the reduced internalisation, as receptor internalisation is significantly increased by EGFR activity [12]. However, exactly how these two outcomes influence the final dynamics of the pathway awaits further characterisation. Interestingly, ERK1/2 activity can also activate the tyrosine phosphatase cdc25c via phosphorylation at T48 [13]. Cdc25c then dephosphorylates the EGFR at Y1068, which is required for its activity, in a negative feedback loop. Therefore, in addition to phosphorylating the receptors directly, ERK1/2 can also activate tyrosine phosphatases that inactivate the EGFR, adding to the number of mechanisms by which upstream RTK signalling can be suppressed by negative feedback.

The fibroblast growth factor (FGF) receptor has also been shown to be subject to ERK1/2 feedback phosphorylation. FGF signalling leads to FGF receptor 1 (FGFR1) phosphorylation on a conserved serine residue (S777) in its C-terminal tail in an ERK1/2-dependent manner [14]. Furthermore, the authors demonstrated that recombinant ERK1 and ERK2 phosphorylate FGFR1 on S777 in vitro. 
Table 1 Negative feedback phosphorylation of ERK1/2 MAPK pathway components

\begin{tabular}{|c|c|c|c|}
\hline Component & Phosphorylation sites & Mechanism & References \\
\hline EGFR & T669 & $\begin{array}{l}\text { Reduces EGFR tyrosine phosphorylation through impaired cross activation of } \\
\text { the receptor dimer }\end{array}$ & {$[7-11]$} \\
\hline FGFR1 & S777 & Reduces FGFR1 tyrosine phosphorylation (unknown mechanism) & {$[14]$} \\
\hline SOS1 & $\begin{array}{l}\text { S1132, S1167, S1178, } \\
\quad \text { S1193 }\end{array}$ & Disrupts association with Grb2 & {$[15-19]$} \\
\hline SOS1 & $\begin{array}{l}\text { S1134, S1161 } \\
\text { (phosphorylated by } \\
\text { RSK2) }\end{array}$ & Creates a 14-3-3 binding site; reduces plasma membrane localisation & {$[20,21]$} \\
\hline FRS $2 \alpha$ & $\begin{array}{l}\text { T132, T135, T138, T376, } \\
\text { T452, T455, T458, T463 }\end{array}$ & Reduces FRS $2 \alpha$ tyrosine phosphorylation; inhibits Grb2 association & {$[23,24]$} \\
\hline LAT & T155 & May disrupt association with PLC $\gamma 1$ & [26] \\
\hline Raf-1 & $\begin{array}{l}\text { S29, S289, S296, S301, } \\
\quad \text { S642 }\end{array}$ & Reduces association with Ras and plasma membrane localisation & {$[15,28-31,33,34]$} \\
\hline B-Raf & S151, T401, S750, T753 & $\begin{array}{l}\text { Disrupts dimerisation with Raf-1 (S151, T401, S750, T753); disrupts } \\
\text { association with Ras (S151) }\end{array}$ & {$[35,36]$} \\
\hline MEK1 & T292, Т386 & $\begin{array}{l}\text { May increase the dephosphorylation of the MEK1 activating sites; interferes } \\
\text { with the activating phosphorylation of MEK1 on S298 by PAK (T292) }\end{array}$ & [38-41] \\
\hline KSR1 & $\begin{array}{l}\text { T260, T274, S320, S443, } \\
\quad \text { S463 }\end{array}$ & $\begin{array}{l}\text { Disrupts association with B-Raf; regulates subcellular localisation } \\
\text { (compartmentalisation) }\end{array}$ & [54-57] \\
\hline
\end{tabular}

The ERK1/2 pathway proteins known to be phosphorylated in a negative feedback loop are listed, together with the phosphorylated residue(s). All sites are directly phosphorylated by ERK1/2, unless specified otherwise. The potential mechanisms by which these modifications regulate the target protein are also listed

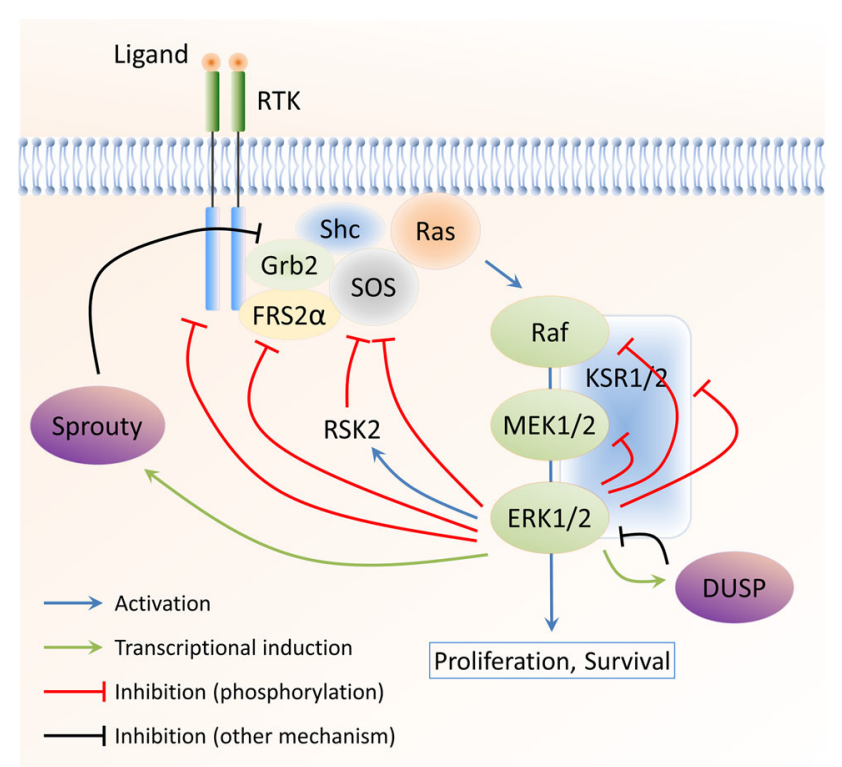

Fig. 1 Negative feedback regulation of the ERK1/2 MAPK pathway. The ERK1/2 MAPK pathway is subject to a large number of negative feedback loops. These include direct phosphorylation by ERK1/2 (and RSK2) as well as transcriptionally induced feedback regulators, such as DUSPs and Sprouty proteins. The major negative feedback loops acting on the ERK1/2 pathway are shown

Importantly, the mutation of S777 to alanine resulted in prolonged FGF1-induced tyrosine phosphorylation of FGFR1. It also increased cell proliferation and migration of
U2OS cells expressing FGFR1, as well as neuronal outgrowth in cultured dorsal root ganglions, two established models of FGFR-stimulated, ERK1/2-dependent cell function. These experiments clearly demonstrate that FGFR1 is subject to direct negative feedback phosphorylation by ERK1/2. It is unclear, however, how this results in decreased FGFR1 tyrosine phosphorylation and attenuated signalling. It is possible that the phosphorylated S777 site acts as a binding site for tyrosine phosphatases, or that S777 phosphorylation induces local conformational changes in FGFR1 that make it a better substrate for dephosphorylation, but these possibilities have yet to be investigated.

Adaptor proteins, exchange factors, and GTP hydrolyase activating proteins

Adaptor proteins connect activated RTKs to Ras and the downstream MAPK cascade. Regardless of continuous growth factor stimulation, Ras activation is usually transient. A negative feedback loop from ERK1/2 to adaptor proteins and exchange factors contributes to this transiency. For example, it was found that MAPK pathway activation results in hyperphosphorylation of SOS1, which was enhanced by ERK overexpression [15] and prevented by MEK1/2 inhibition [16]. It was further shown that SOS1 is phosphorylated in vitro by activated ERK2 at multiple sites [17]. SOS1 phosphorylation disrupts its association 
with the adaptor proteins Grb2 and Shc and, consequently, the receptors at the plasma membrane [16-18]. Interestingly, simulation modelling suggests that the sites phosphorylated by ERK1/2 may act decisively-as opposed to cooperatively-in downregulating SOS1 activity [19]. SOS1 is also phosphorylated by the ERK1/2 effector ribosomal S6 kinase 2 (RSK2) [20]. RSK2-mediated phosphorylation of two sites on SOS1 (S1134 and S1161) leads to the recruitment of 14-3-3 and negative regulation of ERK1/2 activity [21].

The FGF receptor substrate 2 proteins (FRS2 $\alpha$ and FRS2 $\beta$ ) are adaptor proteins that are recruited to activated RTKs via N-terminal PTB domains. They also contain multiple tyrosine phosphorylation sites in their C-termini that allow the binding of the adaptor protein Grb2 [22]. Lax and colleagues [23] found that upon FGF stimulation FRS $2 \alpha$ became phosphorylated on eight threonine residues, all of which were followed by a proline, representing a minimum ERK1/2 consensus sequence. They further showed that expression of dominant-negative Ras or MEK1/2 inhibition abolished this phosphorylation, suggesting that FRS $2 \alpha$ is phosphorylated by an ERK1/2dependent feedback mechanism. Importantly, mutation of the FRS $2 \alpha$ threonine phosphorylation sites enhanced FRS $2 \alpha$ tyrosine phosphorylation and Grb2 association. The same FRS2-dependent mechanism has been reported for the regulation of EGFR signalling [24], suggesting that threonine phosphorylation of FRS $2 \alpha$ by ERK1/2 may represent a conserved mechanism by which to inhibit FRS $2 \alpha$ tyrosine phosphorylation and downregulate RTK signalling.

Another adaptor protein regulated by ERK1/2 feedback phosphorylation is the linker for activation of $\mathrm{T}$ cells (LAT), a single-pass transmembrane protein that is expressed in various immune cells [25]. Upon engagement of the T cell receptor (TCR), tyrosine phosphorylation of LAT leads to the recruitment of several $\mathrm{SH} 2$ domaincontaining proteins, including Grb2, resulting in ERK1/2 activation. Matsuda and colleagues [26] found that LAT can be phosphorylated on T155 by ERK1/2 in vitro. They further showed that this site is phosphorylated upon $\mathrm{T}$ cell activation in a MEK1/2-dependent manner, suggesting that this event represents a feedback mechanism. To this end, they showed that a LAT T155A mutant supported an enhanced degree of TCR signalling (as measured by an increase in intracellular $\mathrm{Ca}^{2+}$ mobilisation) and that abolishing ERK1/2 feedback through a MEK1/2 inhibitor similarly enhanced TCR signalling. Through co-immunoprecipitation experiments, the authors showed that the mechanism behind the inhibitory role of LAT T155 phosphorylation may involve the disruption of the interaction of LAT with its downstream signalling partner, phospholipase C $\gamma 1$ (PLC $\gamma 1$ ), but not Grb2.
A recent paper by Hennig et al. [27] also implicated Ras-GAP proteins as a target of negative feedback regulation of Ras activity. They showed that inhibition or knockdown of MEK1/2, ERK1/2, or RSK in HeLa cells resulted in sustained activity of Ras (evidenced by GTP loading). As the GDP/GTP exchange rate at the later time points was not significantly changed, they concluded that the sustained activity must be due to the inactivation of a Ras-GAP, rather than an exchange factor such as SOS. Through knockdown experiments, the authors then implicated NF1 (neurofibromin) as the likely candidate, as knockdown resulted in similarly sustained Ras activation kinetics as the inhibition of ERK1/2 or Rsk. While it remains to be shown whether NF1 activation by ERK1/2 and Rsk is by direct phosphorylation or if other proteins/ mechanisms are involved, this work adds another route by which the upstream components of the ERK1/2 MAPK cascade can be inhibited through negative feedback.

\section{Raf proteins}

The first suggestion that Raf is subject to feedback phosphorylation was provided by Ueki and colleagues [15], who showed that Raf-1 is hyperphosphorylated after the stimulation of insulin receptor-expressing $\mathrm{CHO}$ cells with either insulin or TPA (12-O-tetradecanoylphorbol 13-acetate). Raf-1 hyperphosphorylation was delayed compared to the activation of Raf-1, MEK1/2 and ERK1/2, and it was further enhanced by overexpression of ERK1, suggesting a negative feedback loop. Further studies showed that Raf-1 hyperphosphorylation is dependent upon MEK1/2 activity [28] and that pharmacological inhibition of ERK1/2 signalling results in increased and more sustained Raf-1 activity compared to its normal transient activation [29, 30]. Hyperphosphorylated Raf-1 also displayed reduced plasma membrane association, indicating a possible mechanism of Raf-1 feedback regulation [28].

A major advancement towards understanding the role of Raf-1 in the negative feedback regulation of ERK1/2 signalling was made by the identification of six Raf- 1 residues that are phosphorylated following mitogenic stimulation [31]. Five of these sites were directly phosphorylated by ERK2 in vitro, and their phosphorylation was dependent on signalling downstream of MEK1/2, suggesting that they are involved in a feedback loop. The identified phosphorylation sites are located close to the N-terminus (S29/S43), the C-terminus (S642), and in the flexible hinge region between the regulatory and catalytic domain (S289/S296/ S301) of Raf-1. Phosphorylation at these sites yielded a desensitised Raf- 1 unable to localise to the plasma membrane and to engage with activated Ras [31]. Feedback phosphorylation also prevented sustained Raf-1 activity $[31,32]$, as was shown by MEK1/2 inhibition as well as 
mutation of the feedback sites. In addition, desensitised (hyperphosphorylated) Raf-1 cannot be activated by stimulation with another growth factor, even though the upstream Ras protein is activated. Interestingly, hyperphosphorylated Raf- 1 is not degraded, but is resensitised by a complex process involving the prolyl isomerase Pin1 and the protein phosphatase PP2A [31]. ERK1/2 activity-dependent phosphorylation of a subset of these sites (S296/ S301) has also been observed by Hekman et al. [33], following expression of an activated Raf-1 mutant in Drosophila Sf9 cells. Importantly, these authors showed that the mutant proteins had significantly increased kinase activity in quiescent and EGF-stimulated mammalian cells, confirming a negative regulatory role for this phosphorylation event. However, while Balan et al. [34] also described phosphorylation of a subset of these sites (S289/ S296/S301) in response to EGF stimulation of COS-7 cells, they found that it rather acts in a stimulatory manner. The reasons for this discrepancy are not clear, but could involve the different cell lines (NIH3T3 vs. COS-7) or growth factors [Platelet-derived growth factor (PDGF) vs. EGF] used. In addition, the ERK1/2 feedback sites located at the $\mathrm{N}$ - and C-terminus of Raf-1 (S29 and S642, respectively) were not characterised by Balan et al. It is possible that phosphorylation of the different sites is hierarchical, with some sites being more important than others. It has also not been clarified if phosphorylation at the multiple sites of Raf- 1 is cooperative or decisive, i.e., whether all sites need to be phosphorylated for a measurable effect on Raf-1 activity. An interesting hypothesis is that Raf- 1 feedback phosphorylation could serve as a sensor for the strength of signalling output, responding differently to weak or strong Raf- 1 activation. To gain more insight into these questions, the relative contribution of each of the identified ERK1/2 feedback sites to the overall regulation of Raf-1 activity clearly needs further investigation.

Feedback phosphorylation at ERK1/2 phosphorylation motifs was also identified within the B-Raf C-terminus (S750 and T753) upon engagement of the B cell antigen receptor in chicken DT40B cells [35]. Mutation of these sites to a phosphomimetic amino acid strongly reduced the ability of B-Raf to induce neurite outgrowth in a PC12 cell system. Interestingly, the S750 site is located in a similar sequence and position to one of the Raf-1 feedback phosphorylation sites (S642) [31]. It has since been shown that two additional sites within B-Raf (S151, T401) are phosphorylated by activated ERK1/2 in response to PDGF treatment of NIH3T3 cells [36]. These sites are located in the N-terminal region of B-Raf (in an equivalent position to S29 of Raf-1) and the flexible hinge region (similar to S289/S296/S301 of Raf-1), respectively. Together, these sites represent an arrangement similar to the feedback sites of Raf-1. They are also subject to Pin1/PP2A-dependent dephosphorylation, which may recycle it to a signallingcompetent state. B-Raf had previously been found to heterodimerise with Raf-1 upon activation by Ras, leading to Raf-1 transactivation [37]. Mutational analysis suggested that ERK1/2 phosphorylation of all four sites within B-Raf contributes to disruption of its dimerisation with Raf-1, whereas phosphorylation at $\mathrm{S} 151$ is solely responsible for inhibiting the interaction with activated Ras [36]. Interestingly, the combined mutant had a stronger oncogenic effect in focus formation assays than the single mutants (other combinations have not been investigated), indicating a degree of additivity.

\section{MEK1/2}

A number of inhibitory, proline-directed phosphorylation sites have been reported for MEK1, including T286, T292, and T386 [38-41]. The T292 site has been described in each of these studies and appears to play the decisive role in inhibiting MEK1 activity. T292 has been shown to be phosphorylated by ERK1 and ERK2 in vitro and its phosphorylation is dependent on ERK1/2 activity in intact cells [38-40]. Phosphorylation of T292 inhibits the in vitro kinase activity of MEK1 towards ERK1/2 [41], and the T292A mutant is activated more strongly by serum treatment [38], indicating a negative regulatory role for T292 phosphorylation. Dephosphorylation and inactivation of MEK1 (and MEK2) has been proposed as a potential mechanism mediating this feedback. Eblen and colleagues [40] further found that ERK1/2 phosphorylation of MEK1 on T292 interferes with the binding of MEK1 to ERK2. It also reduced the ability of PAK (p21-activated kinase) to phosphorylate MEK1 on S298, which is required for the activation of MEK1 by cell adhesion [39, 40, 42]. Interestingly, the equivalent of the T292 site is absent in MEK2. Nevertheless, it has been shown that MEK1 and MEK2 form heterodimers in vivo and that phosphorylation of T292 in MEK1 also reduces the activity of MEK2 in the context of the dimer [43], thus enabling the two MEK proteins to be regulated simultaneously.

\section{KSRI}

A number of scaffold proteins have been shown to regulate MAPK signalling in mammalian cells by organising the signalling components into macromolecular complexes and enhancing the efficiency and specificity of the MAPK signalling cascade [44-46]. KSR (kinase suppressor of Ras) proteins are perhaps the best studied scaffold proteins for the ERK1/2 MAPK pathway. KSR1 was originally identified as a positive regulator of Ras signalling in Drosophila and C. elegans [47-49]. Subsequent analysis found that KSR1 interacts with all three kinases of the 
ERK1/2 cascade [50, 51]. KSR1 has also been shown to translocate from the cytosol to the plasma membrane upon growth factor stimulation [52, 53], thus allowing the assembly of the ERK1/2 pathway (Raf, MEK1/2, and ERK1/2) close to the upstream activators (i.e., activated Ras). Importantly, KSR1 translocation also localises active ERK1/2 into close proximity to Raf-1 and other pathway constituents, potentially facilitating feedback phosphorylation of upstream pathway components.

A number of KSR1 residues (T256, T260, T274, S320, S443, S463) corresponding to the minimum ERK1/2 phosphorylation consensus motif (SP or TP) have been shown to be phosphorylated in cycling cells [54] as well as those stimulated with active Ras or growth factors [55-57]. These sites were also phosphorylated by recombinant ERK1/2 in vitro and their phosphorylation in intact cells depended on MEK1/2 activity [55-57]. KSR1 was also phosphorylated at a subset of these sites when it was immunoprecipitated from cycling HEK293T cells [54], indicating that the responsible kinase(s) associated with KSR1. As activated ERK1/2 associates with KSR1 in a Ras-dependent manner [55], this further suggests that ERK1/2 may directly phosphorylate KSR1.

Phosphorylation of KSR1 at the above sites has been shown to have multiple effects on its function. Mutation of these sites, inhibition of MEK1/2, and blocking ERK1/2 binding to KSR1 all resulted in increased and sustained binding of KSR1 to B-Raf, suggesting that KSR1 feedback phosphorylation interrupts the ternary complex of B-Raf, KSR1, and MEK1/2 [57]. Subsequent co-immunoprecipitation experiments demonstrated that ERK1/2 feedback phosphorylation of KSR1 leads to the release of KSR1 from the plasma membrane, thereby impairing the ability of KSR1 to potentiate signal transduction. KSR1 feedback phosphorylation has also been shown to influence signalling dynamics, as KSR1 feedback mutants show sustained ERK1/2 activation in response to EGF treatment of HEK293 cells [56]. Interestingly, the S443 site has been shown to be the most critical feedback site [56], as mutation of this residue alone resulted in significantly prolonged ERK1/2 activation in HEK293 cells, while further mutation of other sites (T260, T274, and S320) had a small additive effect.

The molecular mechanisms by which feedback phosphorylation of KSR1 regulate signalling were further analysed in detail in neurons [56], where KSR1 is most strongly expressed $[58,59]$. ERK1/2 activity is well known to be required for synaptic plasticity, particularly long-term potentiation (LTP) of synaptic currents, by regulating the amount of glutamate receptors at the cell surface of the postsynaptic compartment, the dendritic spines. Notably, KSR1 has been demonstrated to be located in dendritic spines [56], suggesting for the first time that it may regulate synaptic strength by promoting local ERK1/2 activity in the postsynaptic compartment. Furthermore, it was demonstrated that feedback phosphorylation of KSR1 results in the exclusion of the ERK1/2 scaffold complex from dendritic spines, thus reducing ERK1/2 activity specifically in the postsynaptic compartment. As postsynaptic ERK1/2 activity is essential to promote LTP, the localised decrease of ERK1/2 activity had a significant impact on synaptic plasticity, as shown by electrophysiological experiments [56]. Overall, this study demonstrated that in this system, negative feedback limits compartmentalised signalling output to ensure that it remains within physiologically relevant boundaries.

\section{Summary}

Almost every step in the ERK1/2 MAPK pathway is targeted by negative feedback phosphorylation (Fig. 1), from the growth factor receptors at the plasma membrane to the core components of the cascade (such as Raf-1/B-Raf and MEK1/2) and scaffold proteins, such as KSR1. Of those, the Raf proteins and KSR1 demonstrate complex regulatory mechanisms, are able to interact with several pathway components, and reversibly localise to different subcellular compartments. These two proteins may, therefore, serve as key regulatory elements of the ERK1/2 cascade that can finely tune the dynamics of ERK1/2 signalling in the cell as a whole as well as in specific subcellular compartments.

\section{Transcriptional induction of specific MAPK pathway inhibitors}

In addition to rapid feedback by direct phosphorylation using pre-existing protein kinases, transcriptionally induced mechanisms of feedback control have been described for the ERK1/2 MAPK pathway. These processes are likely to take effect with some delay compared to direct phosphorylation. As such, they would be well suited to modulating the later phases of ERK1/2 signalling dynamics, rather than leading to the rapid termination of signalling. They would also be able to contribute to adjusting steady-state signalling levels under conditions of sustained pathway input. The two major groups of proteins that have been demonstrated to perform this function are discussed below.

\section{MAPK phosphatases}

ERK1/2 require phosphorylation of both threonine and tyrosine residues in the activation loop for full kinase activity. Type $1 / 2 \mathrm{Ser} / \mathrm{Thr}$ phosphatases, protein tyrosine phosphatases, and dual-specificity $\mathrm{Thr} / \mathrm{Tyr}$ phosphatases have all been shown to dephosphorylate and inactivate the 
ERK1/2 proteins [60]. The largest and best studied group of phosphatases that specifically regulate MAPK activity are the dual-specificity MAPK phosphatases (MKPs; reviewed in [61]), a subgroup of the dual-specificity phosphatases (DUSPs). There are ten MKPs in mammalian cells, which can be divided into three groups. The first group comprises the nuclear proteins DUSP1/MKP-1, DUSP2, DUSP4/MKP-2, and DUSP5, which dephosphorylate ERK1/2, p38, and JNK (DUSP5 is ERK1/2-specific). The second group includes the cytoplasmically located ERK1/2-specific phosphatases DUSP6/MKP-3, DUSP7/ MKP-X, and DUSP9/MKP-4, while the final group contains the p38/JNK-specific phosphatases DUSP8 (M3/6), DUSP10/MKP-5, and DUSP16/MKP-7. In addition, a number of atypical DUSPs have been identified. However, atypical DUSPs do not possess a MAPK-binding motif, and their role in the regulation of MAPKs is less clear.

Many members of the DUSP family are immediate early or delayed early genes that can be transcriptionally induced by ERK1/2 MAPK pathway activation [62]. While the degree and the dynamics of induction of the individual DUSPs vary depending on the cell type and the exact stimulus, their inducibility enables these proteins to play an important role in feedback regulation of ERK1/2 activity. For example, in NIH3T3 cells, DUSP6 expression is induced by FGF [63]. This induction is blocked by MEK1/2 inhibition, suggesting that DUSP6 may be involved in pathway feedback. Further analysis demonstrated that upregulation of DUSP6 is mediated by direct binding of the ERK1/2-responsive transcription factor ETS1 to the DUSP6 gene promoter [63, 64]. Overexpression of wild-type DUSP6 reduced the levels of EGF-stimulated phosphoERK1/2 after two hours of stimulation, but a phosphatasedead mutant DUSP6 had no effect [64]. These results indicate that ERK1/2-induced DUSP6 expression leads to feedback inhibition via dephosphorylation of ERK1/2. In addition, due to their restricted distribution, DUSPs can anchor inactive ERK1/2 in the nucleus or the cytoplasm $[65,66]$, potentially delaying their re-activation. It should be noted, however, that DUSPs only act on ERK1/2 and do not regulate the upstream components of the pathway.

\section{Sprouty proteins}

Another group of relatively well-characterised transcriptionally induced inhibitors of ERK1/2 signalling are the sprouty (Spry) proteins [67], originally identified in Drosophila as an inhibitor of Ras signalling downstream of various RTKs [68-70]. In mammals, the expression of all four Spry proteins (Spry1-4) can be induced by growth factor signalling [71, 72]. In particular, Spry2 mRNA expression is induced by various FGF members in human ovarian granulosa lutein cells, murine osteoblastic cells, bovine ovarian granulosa cells, and murine pancreatic buds [73-76]. In several cases, the RTK-mediated induction of Spry expression was abrogated by MEK1/2 inhibition, suggesting that the expression of the Spry proteins depends on ERK1/2 activity and that they may function as feedback modulators [74-76]. Interactions between Spry proteins and several ERK1/2 pathway components have been reported, although how these interactions may allow Spry to modulate signalling remains largely unclear [77]. Nevertheless, one group showed that Spry1 and Spry2 become phosphorylated on a conserved $\mathrm{N}$-terminal tyrosine residue (Y53 or Y55, respectively) upon EGF or FGF stimulation of $\mathrm{C} 2 \mathrm{C} 12$ cells [78]. Phosphorylation at this site creates a docking site for the SH2 domain of Grb2, which leads to the disruption of the association between Grb2 and the FGFR adaptor FRS2. This result suggested that Spry may inhibit signalling upstream of Ras, but other reports indicate that Spry may also inhibit the pathway downstream of Ras, possibly by binding to Raf-1 $[79,80]$. Other mechanisms have been reported, demonstrating that the regulation of ERK1/2 signalling by the Spry proteins is complex and likely depends on cell type and the nature of the stimulus (see [81] for a detailed discussion). Taken together, current data suggest that Spry proteins can be induced by ERK1/2 pathway activation and that they inhibit ERK1/2 signalling by acting at multiple nodes in the pathway in a context-specific manner.

\section{Summary}

A multitude of mechanisms has developed to inhibit ERK1/2 MAPK signalling by negative feedback regulation (Fig. 1). These include relatively fast-acting mechanisms that utilise the downstream components of the cascade (mostly ERK1/2, but also RSK2) to directly modify the activity of various upstream components. In addition, mechanisms have evolved that depend on the de novo expression of proteins, which in turn target the ERK1/2 pathway at multiple levels. These mechanisms are likely to be slower, affecting the later phases of ERK1/2 signalling. This multitude of mechanisms ensures that ERK1/2 signalling dynamics can be controlled in a well-defined manner and that it can be adapted to the particular circumstances of individual tissues and environmental conditions.

\section{Negative feedback modulates ERK1/2 MAPK signalling dynamics}

Temporal regulation of ERK1/2 signalling by negative feedback

ERK1/2 MAPK pathway output is determined by the integration of positive input (e.g., growth factors) and positive and negative regulatory events, such as cross-talk 
and feedback mechanisms. These events determine ERK1/ 2 signalling strength and duration and critically influence the physiological outcomes. In a classic study, Traverse and colleagues reported that in rat PC-12 cells, stimulation with nerve growth factor (NGF) or EGF resulted in neuronal differentiation or proliferation, respectively [82]. These strikingly different responses were linked to differences in the temporal dynamics of ERK1/2 activation, whereby NGF caused sustained ERK1/2 activation and nuclear translocation, while EGF induced a transient response without nuclear translocation of activated ERK1/ 2. Subsequent computer simulations suggested that negative feedback is the major determinant of ERK1/2 dynamics in this system [83]. This analysis was further supported by Santos and colleagues [84] using modular response analysis. Feeding data generated from pathway perturbations by RNA interference into a sensitivity analysis produced evidence of a negative feedback loop from ERK1/2 to Raf-1 when the pathway was stimulated with EGF, but a positive loop when stimulated with NGF. These findings were substantiated by the demonstration that through rewiring the relevant feedback systems using pharmacological compounds and inhibitors, the dynamics of ERK1/2 activation and cell fate could be reversed in each of the NGF- or EGF-stimulated states [84]. Interestingly, differential expression of scaffold proteins, such as KSR1, can also significantly modulate ERK1/2 dynamics in PC-12 cells. Simply increasing the concentration of the KSR1 scaffold has been shown to convert the temporary ERK1/2 signal resulting from EGF stimulation into a sustained one and to change cellular outcome from proliferation to differentiation [58]. Interestingly, ERK1/2 signalling dynamics have a similar, albeit reverse effect on adipogenesis [85]. Low concentrations of KSR1 promote ERK1/2 activation, C/EBP $\beta$ phosphorylation, and adipogenesis. In contrast, higher concentrations of KSR1 were shown to prolong ERK1/2 signalling [86], promote PPAR $\gamma$ phosphorylation and inactivation, and inhibit differentiation (adipogenesis) in favour of proliferation [85, 86]. Together, these reports clearly highlight the power of feedback mechanisms to shape MAPK signalling outputs and the resulting physiological outcomes and suggest the existence of growth factor-specific network topologies.

Subsequent modelling approaches have further illuminated the role of negative feedback in determining ERK1/2 signalling outputs. Elegant combinatorial work by Sturm and colleagues [87] showed that the ERK1/2 MAPK pathway exhibits properties of a negative feedback amplifier (NFA). Importantly, the presence of negative feedback confers graded response characteristics (as opposed to a switch-like pattern when negative feedback is broken), robustness to change and stabilisation of output. The robustness conferred by negative feedback was further demonstrated in experiments showing that the level of steady-state doubly-phosphorylated ERK1/2 ('output') was only weakly dependent on ERK1/2 protein concentration [88], ensuring a reliable interpretation of extracellular signals under fluctuating conditions. The authors further showed that this robustness was lost in cells expressing constitutively active B-Raf mutants or a constitutively active Raf-1 protein, but not Ras mutants. As constitutively active B-Raf (or Raf-1) is not sensitive to negative feedback regulation, these experiments suggest that the robustness of the pathway output is critically dependent on negative feedback targeting Raf-1 [31].

\section{Spatial regulation of ERK1/2 signalling by negative feedback}

Many cellular processes occur in specialised subcellular compartments, and the localisation of ERK1/2 activity to those specific areas is critical to cellular function [1]. Modulating the subcellular localisation of activated ERK1/ 2, even without changing overall cellular ERK1/2 activity, can significantly change the availability of ERK1/2 for a particular molecular function, with important consequences for the outcome of signalling. Several cases have been described where feedback phosphorylation leads to the disassembly of the signalling complexes, resulting in the removal of components from the plasma membrane and termination of signalling [16-18, 31]. In addition, reversible spatial segregation of ERK1/2 pathway components by negative feedback has been demonstrated [56]. As described earlier, the scaffold protein KSR1 is subject to feedback phosphorylation by ERK1/2 at multiple sites. KSR1 is highly expressed in neurons [58], where it is involved in LTP (long-term potentiation), a process important for learning and memory [59]. Its localisation in primary hippocampal neurons was, therefore, further investigated. It emerged that mutant KSR1 that is unable to undergo feedback phosphorylation was preferentially present in dendritic spines of the neurons, where it colocalised with activated ERK1/2. In contrast, hyperphosphorylated KSR1 was largely absent from dendritic spines and resided in the dendritic processes. Importantly, MEK1/2 inhibition or reduction of neuronal activity by tetrodotoxin (TTX) resulted in the relocalisation of wild-type KSR1 to dendritic spines, demonstrating that the localisation of the KSR1 scaffold is reversibly regulated by neuronal activity and ERK1/2-dependent negative feedback. Localised ERK1/2 signalling in dendritic spines has been shown to be important for LTP and memory retention [89]. Consequently, the expression of a mutant KSR1 lacking ERK1/2 feedback phosphorylation sites in cultured hippocampal neurons led to increased KSR1 concentrations and phospho-ERK1/2 staining in dendritic spines and prolonged 
LTP of synaptic currents compared to wild-type KSR1. A model was proposed in which KSR1 tightly regulates MAPK cascade output in the postsynaptic compartment (dendritic spines) via compartmentalisation of the ERK1/2 signalling module. In resting neurons, KSR1 is localised to the postsynaptic compartment, where it scaffolds Raf, MEK1/2, and ERK1/2, making the synapse highly sensitive to Ras-activating signals that promote LTP. However, as more ERK1/2 is activated, feedback phosphorylation of KSR1 gradually removes it from the dendritic spines, making the system less sensitive and protecting against excessive ERK1/2 activity in the postsynaptic compartment. These results clearly demonstrate that negative feedback is able to direct the signalling complexes to different subcellular compartments, in addition to regulating their assembly and disassembly.

\section{Negative feedback regulation of ERK1/2 signalling in cancer progression and treatment}

Aberrant ERK1/2 activation results in deregulated proliferation and malignant transformation in model systems and is commonly observed in human tumours. Inhibition of the ERK1/2 pathway, therefore, represents an attractive target for the treatment of malignant tumours with increased ERK1/2 activity. However, therapeutic agents targeting the ERK1/2 pathway would be expected to also inhibit the substantial negative feedback loops (see Fig. 1), with important consequences for therapeutic response and the development of drug resistance.

\section{Sensitivity to negative feedback determines the response to therapeutic inhibitors}

Activation of the ERK1/2 pathway is typically a result of mutations in members of the RAS and RAF gene families or the amplification and hyperactivation of RTKs [90-93]. Importantly, oncogenic B-Raf mutations are much more common than those in A-Raf or Raf-1. While A-Raf and Raf-1 require phosphorylation of two regions within their kinase domain for full activation [3], B-Raf contains two phosphomimetic aspartic acid residues and a constitutively phosphorylated serine at the equivalent positions [94]. Therefore, B-Raf has higher basal activity and requires only a single mutation within its kinase domain to switch to constitutively high activity. Such substitutions are frequently observed in ERK1/2-dependent tumours, most commonly the V600E mutation. Interestingly, tumours with B-RAF mutation are sensitive to inhibition of MEK1/ 2 , whereas tumours with hyperactivated growth factor receptors are not [95]. Reasons for this discrepancy and potential ways to overcome these challenges are discussed below.
In cells with mutations in upstream components (e.g., RTKs or Ras) and expressing wild-type Raf proteins, negative feedback mechanisms significantly reduce the activity of several upstream pathway components, leading to relatively low (but still elevated) levels of MEK1/2 and ERK1/2 activity (Fig. 2a). Inhibition of MEK1/2 or Raf will weaken the negative feedback loops, leading to an increase in MEK1/2 and ERK1/2 activation. Therefore, a significantly higher inhibitor concentration is necessary for full inhibition of ERK1/2 signalling. This behaviour has been predicted by Sturm et al. [87], as loss of negative feedback is expected to increase the gain of the negative feedback amplifier (NFA) module, conferring robustness from external perturbations to the system. While this regulation helps to maintain signalling fidelity in normal cells, it also contributes to the development of intrinsic resistance to inhibitors. In addition, loss of negative feedback inhibition in these tumours results in increased levels of RasGTP, which has been shown to promote the dimerisation of Raf proteins [37, 96, 97]. As binding of a Raf inhibitor to one protomer can allosterically activate the other, Raf inhibition results in the paradoxical promotion, rather than inhibition, of ERK1/2 signalling [98, 99]. Importantly, the observed transcriptional output of tumour cells with mutated RTKs or Ras is only partially driven by ERK1/2 activity [100], with the activation of parallel pathways significantly contributing to the expression of mitogenic genes. In many cancers with upstream mutations, MEK1/2 or Raf inhibitors, therefore, do not result in therapeutic changes of gene expression. In this context, Sturm and colleagues [87] suggested that inhibiting targets outside of the NFA is likely to be more effective. Their modelling studies also raise the possibility of targeting modulators of ERK1/2 activity, such as scaffold proteins, either alone or in combination with Raf or MEK1/2 inhibitors. A related conclusion from their modelling was that the inhibition of the feedback loops themselves would likely lead to a new steady-state activity of the pathway that is not subject to negative feedback, thus enhancing the efficacy of inhibition by MEK1/2 or Raf inhibitors. This was demonstrated in a study in which SPRY2 silencing using siRNA improved the inhibition of proliferation by a Raf inhibitor [101].

In contrast to tumours with upstream activation (RTKs or Ras), those harbouring mutant B-Raf are generally sensitive to MEK1/2 or Raf inhibition. One reason for this sensitivity is that mutant B-Raf is constitutively active and insensitive to negative feedback (Fig. 2b). Hyperactivation of MEK1/2 (and ERK1/2) in B-Raf-mutated cells, therefore, continues unabated, resulting in increased transcriptional output of transforming genes with ERK1/2 being the major driver [100]. However, the induced genes include, in addition to those required for transformation, negative feedback regulators, such as DUSPs and sprouty 


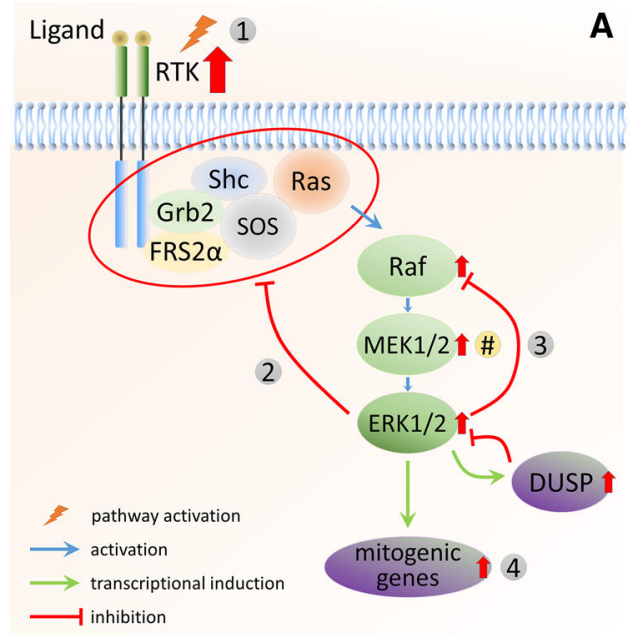

Fig. 2 ERK1/2 MAPK signalling in response to different oncogenic stimuli. a In cells with mutation or amplification of upstream components [e.g., RTKs (1)] and expressing wild-type Raf proteins, negative feedback mechanisms are highly active $(2,3)$ and significantly reduce the activity of several upstream pathway components. This leads to relatively low (but still elevated) steady-state levels of MEK1/2 and ERK1/2 activity. When either Raf or MEK1/2 are inhibited, this negative feedback is reduced. As a result, signal flux is increased, restoring MEK1/2 and ERK1/2 activity and requiring significantly higher inhibitor doses (intrinsic resistance). Loss of negative feedback (2) due to pathway inhibition also results in increased Ras-GTP levels, which promotes the dimerisation of wildtype Raf proteins and results in the paradoxical promotion, rather than inhibition, of ERK1/2 signalling. Finally, the observed transcriptional output (4) of tumour cells with mutated RTKs or Ras is only partially driven by ERK1/2 activity because of the relatively small increase in the overall signalling flux due to extensive negative feedback.

proteins. This has two important consequences. First, negative feedback by the sprouty proteins means that RasGTP levels are low. This was demonstrated in B-Raf ${ }^{\mathrm{V} 600 \mathrm{E}}$ melanoma cells, where Ras-GTP levels could be increased by disrupting feedback via either Raf or MEK1/2 inhibition or knockdown of Spry1/2 [102]. In B-Raf ${ }^{\mathrm{V} 600 \mathrm{E}}$ cells, B-Raf therefore exists mostly as a monomer, which is sensitive to inhibition by Raf inhibitors [103]. In addition, the increased expression of DUSPs in B-Raf mutant cells leads to the dephosphorylation of ERK1/2 and a reduction of its apparent activity to levels that support oncogenic transformation (rather than senescence; [104, 105]). Nevertheless, due to the increased transcriptional output of these cells, several genes are induced that are essential for tumour progression. As their expression critically depends on ERK1/2 activity, those tumours are sensitive to inhibition of MEK1/2 or B-Raf. In other words, cells that evade negative feedback become sensitive to inhibition at the level of, or downstream of, the initiating mutation (i.e., $\left.\mathrm{B}-\mathrm{Raf}^{\mathrm{V} 600 \mathrm{E}}\right)$, as those cells have lost their robustness to perturbations conferred by the negative feedback loops.

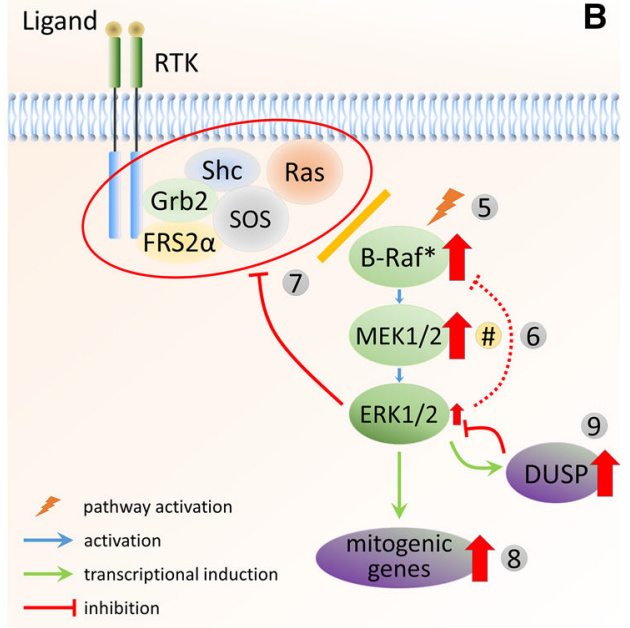

Inhibition of Raf or MEK1/2, therefore, does not sufficiently reduce the expression of those mitogenic genes to result in therapeutic changes. b Mutant B-Raf (5) is constitutively active and, therefore, not sensitive to direct feedback phosphorylation by ERK1/2 (6). In addition, as mutated B-Raf is independent of upstream activation, negative feedback to the upstream components has no effect on B-Raf activity (7). Because mutated B-Raf bypasses negative feedback, persistent hyperactivation of MEK1/2 (and ERK1/2) results in significantly increased transcriptional output of mitogenic genes (8). As mitogenic gene expression critically depends on high signalling flux through the pathway, those tumours are sensitive to the inhibition of MEK $1 / 2$ or B-Raf. In addition, the increased expression of DUSPs (9) in B-Raf mutant cells leads to the dephosphorylation of ERK1/2 and a reduction of its apparent activity to levels that support oncogenic transformation (rather than senescence). As a result, MEK1/2 (rather than ERK1/2) activity is a major hallmark and determinant of inhibitor selectivity (\#)

This has been shown to be the case in vitro [106, 107], and a remarkably high degree of clinical efficacy has been achieved using Raf and MEK1/2 inhibitors in patients with B-Raf-mutant melanoma [108, 109]. It is, therefore, important that tumours are evaluated for their specific mutation to make an informed decision regarding the treatment options. In addition, as MEK1/2 (rather than ERK1/2) activity is a major hallmark and determinant of inhibitor selectivity (see Fig. 2), this could be used as an effective biomarker to stratify patients for treatment with either Raf, MEK1/2, or other inhibitors. Unfortunately, since Raf inhibition in normal cells expressing wild-type Raf proteins activates the ERK1/2 pathway due to relief of negative feedback and the increased formation and activation of Raf dimers, treatment with these compounds can cause ectopic ERK1/2 signalling, with cutaneous lesions (squamous cell carcinoma and/or keratoacanthoma) among the most common problems [110, 111]. However, these side effects are well manageable by surgical excision. In addition, it would be feasible to utilise combination treatments that counter the effects caused by disruption of 
negative feedback in healthy cells to increase the efficacy of the treatment as well as to reduce the potential side effects.

\section{Negative feedback and the development of resistance to ERK1/2 pathway inhibitors}

Inhibitors of B-Raf and MEK1/2 are showing substantial promise in the clinic, particularly for those tumours harbouring B-Raf mutations (see above). However, even patients who respond well to these inhibitors show signs of relapse after several months, indicating that resistance to these inhibitors has developed (adaptive resistance) $[112,113]$. The main reason for resistance in tumours that are originally sensitive to B-Raf or MEK1/2 inhibitors is the re-activation of signal flux through the ERK1/2 pathway [102], resulting in increased transcription of mitogenic genes. Due to the complexity of the regulation of ERK1/2 signalling, there are many potential means by which this can be achieved. Here, we will focus on the mechanisms that are related to relief from negative feedback.

In B-Raf ${ }^{\mathrm{V} 600 \mathrm{E}}$ tumours, Ras activity is suppressed by negative feedback (Fig. 2b). Raf or MEK1/2 inhibition results in the rapid and nearly complete downregulation of ERK1/2 activity. As negative feedback partly depends on inhibitory proteins induced by ERK1/2 signalling (such as sprouty), this inhibition results in a gradual return to lower levels of negative feedback, dependent on relatively slow processes such as protein degradation. While Ras activity remains low at first because of the relatively low activity of upstream components such as RTKs, the cell is returned to a signalling-competent state, where Ras and other upstream factors are able to respond to signal activation (Fig. 3). Indeed, activation of Ras via mutation or overexpression, downregulation of the Ras negative regulator NF1, or upstream RTK overexpression and activation have been associated with resistance to Raf inhibitors in several studies [114-120]. As a result of increased Ras activation, signal flux is increased, promoting higher ERK1/2 activity and requiring higher inhibitor doses. In addition, the relief of ERK1/2-dependent feedback, together with the activation of upstream components, eventually leads to increased levels of Ras-GTP-dependent Raf dimers, which are insensitive to Raf inhibition [99]. Raf dimerisation can also result from increased expression of B-Raf or Raf-1, leading to the re-establishment of elevated ERK1/2 signalling [114, 121, 122]. Evidence for the role of Raf dimerisation in drug resistance was provided in co-immunoprecipitation experiments, which showed that MEK1/2 inhibition increased the formation of Raf-1/B-Raf dimers in melanoma cells [102]. Importantly, knockdown of Raf-1 by siRNA had no effect on basal phospho-ERK1/2 levels in $\mathrm{B}-\mathrm{Raf}^{\mathrm{V} 600 \mathrm{E}}$ cells, but did reduce the extent of rebound of

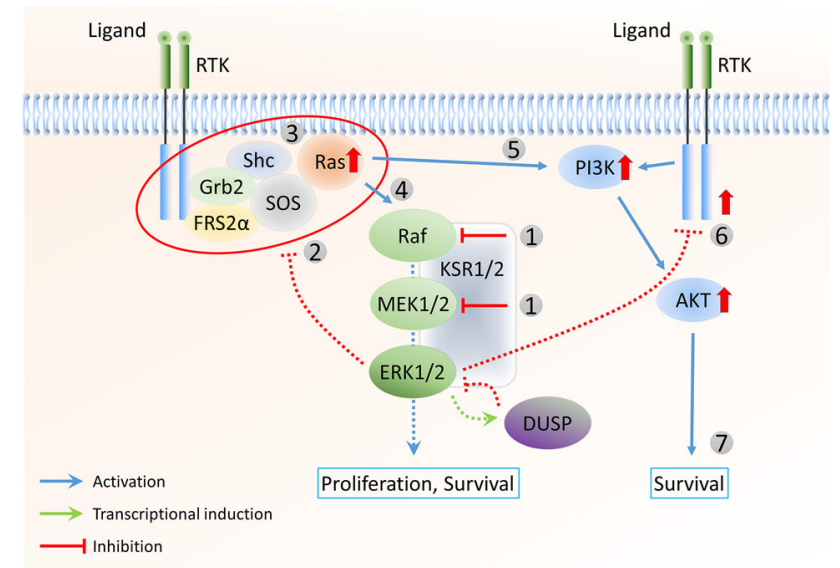

Fig. 3 Loss of negative feedback contributes to resistance to Raf and MEK1/2 inhibitors. Raf or MEK1/2 inhibition (1) results in lower levels of negative feedback to upstream components (2). As a result, the cell is returned to an RTK signalling-competent state, where Ras and other upstream factors are able to respond to signal activation (3). Therefore, signal flux is increased (4), promoting higher ERK1/2 activity and requiring higher inhibitor doses. The increased Ras activity can also activate parallel pathways, such as the PI3K/Akt pathway (5). In addition, loss of negative feedback leads to the derepression of other RTK receptors (6), allowing different growth factors to activate downstream signalling pathways. Activation of the PI3K/Akt pathway can promote cell survival (7) and reduce the dependency of the tumour on ERK1/2 signalling, likely contributing to the acquired resistance to Raf and MEK1/2 inhibitors

phospho-ERK1/2 following prolonged vemurafenib treatment. Interestingly, B-Raf mutant colon cancer cells already express significant levels of the EGFR. Inhibitors of Raf or MEK1/2, therefore, immediately upregulate EGFR activity, due to relief from negative feedback [13]. While melanoma cells require another genetic event, such as EGFR overexpression, to develop resistance, $\mathrm{B}-\mathrm{Raf}^{\mathrm{V} 600 \mathrm{E}}$-positive colon cancer cells are already resistant to Raf or MEK1/2 inhibition and do not respond to treatment with vemurafenib [123].

As described above, Raf inhibition leads to an eventual steady state that is defined by a low level of negative feedback to upstream components, thus permitting Ras activation and responsiveness to RTK stimulation. Nevertheless, it follows that high flux through the pathway, once resistant to Raf inhibitors, is still sensitive to inhibition either upstream or downstream of Raf. The rationale behind this strategy is that the first drug will reduce the negative feedback in the system, increasing the sensitivity of the pathway to inhibition by the second drug. This observation led to the idea that co-targeting several points in the pathway may achieve the required near-total inhibition of ERK1/2 activity (and signal flux) and improve responses in patients with B-Raf ${ }^{\mathrm{V} 600 \mathrm{E}}$ melanoma [124]. Support for this idea has been gained from data showing more complete ERK1/2 inhibition and greater tumour 
regression in mouse xenograft models using combined Raf and MEK1/2 inhibition compared to Raf inhibition alone [102]. Promising early clinical trials suggest that these results may translate into increased therapeutic benefit [125, 126]. In addition, recent studies [103, 127] reported novel Raf inhibitors that are able to bind and inhibit both Raf monomers and dimers. These drugs may be able to address some of the resistance mechanisms, particularly in tumours with acquired resistance that is due to Raf dimerisation.

Unfortunately, the approach to specifically target ERK1/ 2 MAPK signalling - even with combination therapy-is not completely effective, since the relief of ERK1/2 feedback by Raf or MEK1/2 inhibition also reduces the inhibition of parallel pathways that can promote survival and reduce the dependency of the tumour on ERK1/2 signalling (Fig. 3). Several studies have shown that prolonged Raf inhibitor treatment of B-Raf ${ }^{\mathrm{V} 600 \mathrm{E}}$ melanoma cell lines results in the activation of the phosphatidylinositol-3-kinase (PI3K)/Akt pathway. This may occur as a result of increased activity of different RTKs, due to the release of negative feedback acting at this level. For example, Villanueva and colleagues [128] showed that, upon prolonged B-Raf inhibition, several melanoma cell lines displayed increased phosphorylation and expression of insulin-like growth factor 1 (IGF-1) receptor (IGF-1R) as well as enhanced phosphorylation of Akt. In addition, Turke et al. [10] demonstrated that MEK1/2 inhibition reduces phosphorylation of the EGFR feedback site T669, increases the activity of EGFR/ERBB3, and, consequently, activates the PI3K/Akt pathway. Rapid Akt activation by vemurafenib has also been shown in colon cancer cell lines, due to constitutive EGFR expression and the relief of negative feedback by the drug [13]. These observations present the PI3K/Akt pathway as a potential co-target alongside the ERK1/2 pathway in the treatment of B-Raf mutant melanoma and other B-Raf-driven tumours [129, 130]. Consistent with this, co-inhibition of MEK1/2 and IGF-1R or PI3K was more effective in inducing cell death in B-Raf inhibitor-resistant melanoma cells than when either inhibitor was used alone [128]. In addition, combination therapy with vemurafenib and the EGFR inhibitor panitumumab has shown promising results in early trials of B-Raf ${ }^{\mathrm{V} 600 \mathrm{E}}$-positive colon cancer [131] and cotreatment of colon cancer cells with vemurafenib and an EGFR (cetuximab or gefitinib) or Akt (LY294002) inhibitor was synergistic in reducing their growth [13, 132]. Another study found that tyrosine phosphorylation of the EGFR family member ERBB3 was consistently upregulated upon prolonged treatment of four melanoma cell lines with the Raf inhibitor vemurafenib [133]. Under these conditions, Akt phosphorylation was also induced, whereas incubating the cells with a monoclonal anti-ERBB3 antibody completely abrogated the increase in phosphorylation of ERBB3 receptor and Akt. Moreover, coincubation with the anti-ERBB3 antibody was shown to potentiate the growth inhibition effects of vemurafenib in in vitro colony formation assays, inferring the possible clinical use of combining the two approaches.

Overall, these studies demonstrate the importance of understanding the mechanisms that are activated upon relief of ERK1/2-dependent negative feedback, as those efficiently promote drug resistance, particularly in B-Raf ${ }^{\mathrm{V} 600 \mathrm{E}}$ tumours. They also highlight the fact that multiple RTKs and signalling pathways can become activated to rescue antiapoptotic signalling. One proposed approach to circumvent this problem is the genomic and proteomic testing of tumour samples early in and during the treatment phase [113], which would permit the identification of patient-specific mutations as well as RTK activity to inform treatment decisions. Such diagnostic tests would indicate which other pathways may need to be co-targeted, ideally before the eventual emergence of resistance.

\section{Final remarks}

The regulation of the ERK1/2 MAPK pathway is complex and includes numerous negative feedback loops. This negative feedback has likely developed to confer robustness and effective control over this evolutionally conserved signalling pathway. While essential for the normal functioning of the cell, its ability to "rewire" signalling pathways represents a major problem for clinical intervention. Substantial progress has been made during the last few decades in understanding the complex regulation of ERK1/2 MAPK signalling. While there are still a large number of open questions, we are starting to see the benefits of applying this knowledge to targeted cancer treatment in the clinic.

Open Access This article is distributed under the terms of the Creative Commons Attribution 4.0 International License (http:// creativecommons.org/licenses/by/4.0/), which permits unrestricted use, distribution, and reproduction in any medium, provided you give appropriate credit to the original author(s) and the source, provide a link to the Creative Commons license, and indicate if changes were made.

\section{References}

1. McKay MM, Morrison DK (2007) Integrating signals from RTKs to ERK/MAPK. Oncogene 26(22):3113-3121

2. Gureasko J, Galush WJ, Boykevisch S, Sondermann H, Bar-Sagi D, Groves JT, Kuriyan J (2008) Membrane-dependent signal integration by the Ras activator Son of sevenless. Nat Struct Mol Biol 15(5):452-461 
3. Chong H, Vikis HG, Guan K-L (2003) Mechanisms of regulating the Raf kinase family. Cell Signal 15(5):463-469

4. Lavoie H, Therrien M (2015) Regulation of RAF protein kinases in ERK signalling. Nat Rev Mol Cell Biol 16(5):281-298

5. Hagemann C, Rapp UR (1999) Isotype-specific functions of Raf kinases. Exp Cell Res 253(1):34-46

6. Yoon S, Seger R (2006) The extracellular signal-regulated kinase: multiple substrates regulate diverse cellular functions. Growth Factors 24(1):21-44

7. Northwood IC, Gonzalez FA, Wartmann M, Raden DL, Davis RJ (1991) Isolation and characterization of two growth factorstimulated protein kinases that phosphorylate the epidermal growth factor receptor at threonine 669. J Biol Chem 266(23):15266-15276

8. Takishima K, Griswold-Prenner I, Ingebritsen T, Rosner MR (1991) Epidermal growth factor (EGF) receptor T669 peptide kinase from 3T3-L1 cells is an EGF-stimulated "MAP" kinase. Proc Natl Acad Sci USA 88(6):2520-2524

9. Sato K, Shin M-S, Sakimura A, Zhou Y, Tanaka T, Kawanishi M, Kawasaki Y, Yokoyama S, Koizumi K, Saiki I, Sakurai H (2013) Inverse correlation between Thr-669 and constitutive tyrosine phosphorylation in the asymmetric epidermal growth factor receptor dimer conformation. Cancer Sci 104(10): 1315-1322

10. Turke AB, Song Y, Costa C, Cook R, Arteaga CL, Asara JM, Engelman JA (2012) MEK inhibition leads to PI3K/AKT activation by relieving a negative feedback on ERBB receptors. Cancer Res 72(13):3228-3237

11. Li X, Huang Y, Jiang J, Frank SJ (2008) ERK-dependent threonine phosphorylation of EGF receptor modulates receptor downregulation and signaling. Cell Signal 20(11):2145-2155

12. Sorkin A, Goh LK (2009) Endocytosis and intracellular trafficking of ErbBs. Exp Cell Res 315(4):683-696

13. Prahallad A, Sun C, Huang S, Di Nicolantonio F, Salazar R, Zecchin D, Beijersbergen RL, Bardelli A, Bernards R (2012) Unresponsiveness of colon cancer to BRAF(V600E) inhibition through feedback activation of EGFR. Nature 483(7387):100-103

14. Zakrzewska M, Haugsten EM, Nadratowska-Wesolowska B, Oppelt A, Hausott B, Jin Y, Otlewski J, Wesche J, Wiedlocha A (2013) ERK-mediated phosphorylation of fibroblast growth factor receptor 1 on Ser777 inhibits signaling. Sci Signal 6(262):ra11

15. Ueki K, Matsuda S, Tobe K, Gotoh Y, Tamemoto H, Yachi M, Akanuma Y, Yazaki Y, Nishida E, Kadowaki T (1994) Feedback regulation of mitogen-activated protein kinase kinase kinase activity of c-Raf-1 by insulin and phorbol ester stimulation. J Biol Chem 269(22):15756-15761

16. Langlois WJ, Sasaoka T, Saltiel AR, Olefsky JM (1995) Negative feedback regulation and desensitization of insulin- and epidermal growth factor-stimulated p21ras activation. J Biol Chem 270(43):25320-25323

17. Corbalan-Garcia S, Yang SS, Degenhardt KR, Bar-Sagi D (1996) Identification of the mitogen-activated protein kinase phosphorylation sites on human Sos1 that regulate interaction with Grb2. Mol Cell Biol 16(10):5674-5682

18. Porfiri E, McCormick F (1996) Regulation of epidermal growth factor receptor signaling by phosphorylation of the Ras exchange factor hSOS1. J Biol Chem 271(10):5871-5877

19. Kamioka Y, Yasuda S, Fujita Y, Aoki K, Matsuda M (2010) Multiple decisive phosphorylation sites for the negative feedback regulation of SOS1 via ERK. J Biol Chem 285(43):33540-33548

20. Douville E, Downward J (1997) EGF induced SOS phosphorylation in PC12 cells involves P90 RSK-2. Oncogene 15(4):373-383
21. Saha M, Carriere A, Cheerathodi M, Zhang X, Lavoie G, Rush J, Roux PP, Ballif BA (2012) RSK phosphorylates SOS1 creating 14-3-3-docking sites and negatively regulating MAPK activation. Biochem J 447(1):159-166

22. Kouhara H, Hadari YR, Spivak-Kroizman T, Schilling J, BarSagi D, Lax I, Schlessinger J (1997) A lipid-anchored Grb2binding protein that links FGF-receptor activation to the Ras/ MAPK signaling pathway. Cell 89(5):693-702

23. Lax I, Wong A, Lamothe B, Lee A, Frost A, Hawes J, Schlessinger J (2002) The docking protein FRS2 $\alpha$ controls a MAP kinase-mediated negative feedback mechanism for signaling by FGF receptors. Mol Cell 10(4):709-719

24. Wu Y, Chen Z, Ullrich A (2003) EGFR and FGFR signaling through FRS2 is subject to negative feedback control by ERK1/ 2. Biol Chem 384(8):1215-1226

25. Fuller DM, Zhang W (2009) Regulation of lymphocyte development and activation by the LAT family of adapter proteins. Immunol Rev 232(1):72-83

26. Matsuda S, Miwa Y, Hirata Y, Minowa A, Tanaka J, Nishida E, Koyasu S (2004) Negative feedback loop in T-cell activation through MAPK-catalyzed threonine phosphorylation of LAT. EMBO J 23(13):2577-2585

27. Hennig A, Markwart R, Wolff K, Schubert K, Cui Y, Prior IA, Esparza-Franco MA, Ladds G, Rubio I (2016) Feedback activation of neurofibromin terminates growth factor-induced Ras activation. Cell Commun Signal 14(1):5

28. Wartmann M, Hofer P, Turowski P, Saltiel AR, Hynes NE (1997) Negative modulation of membrane localization of the Raf-1 protein kinase by hyperphosphorylation. J Biol Chem 272(7):3915-3923

29. Alessi DR, Cuenda A, Cohen P, Dudley DT, Saltiel AR (1995) PD 098059 is a specific inhibitor of the activation of mitogenactivated protein kinase kinase in vitro and in vivo. $\mathrm{J}$ Biol Chem 270(46):27489-27494

30. Weiss RH, Maga EA, Ramirez A (1998) MEK inhibition augments Raf activity, but has variable effects on mitogenesis, in vascular smooth muscle cells. Am J Physiol 274(6 Pt 1):C1521C1529

31. Dougherty MK, Müller J, Ritt DA, Zhou M, Zhou XZ, Copeland TD, Conrads TP, Veenstra TD, Lu KP, Morrison DK (2005) Regulation of Raf-1 by direct feedback phosphorylation. Mol Cell 17(2):215-224

32. Müller J, Morrison DK (2002) Assay of Raf-1 activity. Methods Enzymol 345:490-498

33. Hekman M, Fischer A, Wennogle LP, Wang YK, Campbell SL, Rapp UR (2005) Novel C-Raf phosphorylation sites: serine 296 and 301 participate in Raf regulation. FEBS Lett 579(2):464-468

34. Balan V, Leicht DT, Zhu J, Balan K, Kaplun A, Singh-Gupta V, Qin J, Ruan H, Comb MJ, Tzivion G (2006) Identification of novel in vivo Raf-1 phosphorylation sites mediating positive feedback Raf-1 regulation by extracellular signal-regulated kinase. Mol Biol Cell 17(3):1141-1153

35. Brummer T, Naegele H, Reth M, Misawa Y (2003) Identification of novel ERK-mediated feedback phosphorylation sites at the C-terminus of B-Raf. Oncogene 22(55):8823-8834

36. Ritt DA, Monson DM, Specht SI, Morrison DK (2010) Impact of feedback phosphorylation and Raf heterodimerization on normal and mutant B-Raf signaling. Mol Cell Biol 30(3):806-819

37. Weber CK, Slupsky JR, Kalmes HA, Rapp UR (2001) Active Ras induces heterodimerization of $\mathrm{cRaf}$ and BRaf. Cancer Res 61(9):3595-3598

38. Brunet A, Pagès G, Pouyssègur J (1994) Growth factor-stimulated MAP kinase induces rapid retrophosphorylation and inhibition of MAP kinase kinase (MEK1). FEBS Lett 346(2-3):299-303 
39. Coles LC, Shaw PE (2002) PAK1 primes MEK1 for phosphorylation by Raf-1 kinase during cross-cascade activation of the ERK pathway. Oncogene 21(14):2236-2244

40. Eblen ST, Slack-Davis JK, Tarcsafalvi A, Parsons JT, Weber MJ, Catling AD (2004) Mitogen-activated protein kinase feedback phosphorylation regulates MEK1 complex formation and activation during cellular adhesion. Mol Cell Biol 24(6):2308-2317

41. Rossomando AJ, Dent P, Sturgill TW, Marshak DR (1994) Mitogen-activated protein kinase kinase 1 (MKK1) is negatively regulated by threonine phosphorylation. Mol Cell Biol 14(3):1594-1602

42. Slack-Davis JK, Eblen ST, Zecevic M, Boerner SA, Tarcsafalvi A, Diaz HB, Marshall MS, Weber MJ, Parsons JT, Catling AD (2003) PAK1 phosphorylation of MEK1 regulates fibronectinstimulated MAPK activation. J Cell Biol 162(2):281-291

43. Catalanotti F, Reyes G, Jesenberger V, Galabova-Kovacs G, de Matos Simoes R, Carugo O, Baccarini M (2009) A Mek1-Mek2 heterodimer determines the strength and duration of the Erk signal. Nat Struct Mol Biol 16(3):294-303

44. Brown MD, Sacks DB (2009) Protein scaffolds in MAP kinase signalling. Cell Signal 21(4):462-469

45. Casar B, Arozarena I, Sanz-Moreno V, Pinto A, Agudo-Ibáñez L, Marais R, Lewis RE, Berciano MT, Crespo P (2009) Ras subcellular localization defines extracellular signal-regulated kinase 1 and 2 substrate specificity through distinct utilization of scaffold proteins. Mol Cell Biol 29(5):1338-1353

46. Zeke A, Lukács M, Lim WA, Reményi A (2009) Scaffolds: interaction platforms for cellular signalling circuits. Trends Cell Biol 19(8):364-374

47. Kornfeld K, Hom DB, Horvitz HR (1995) The ksr-1 gene encodes a novel protein kinase involved in Ras-mediated signaling in C. elegans. Cell 83(6):903-913

48. Therrien M, Chang HC, Solomon NM, Karim FD, Wassarman DA, Rubin GM (1995) KSR, a novel protein kinase required for RAS signal transduction. Cell 83(6):879-888

49. Sundaram M, Han M (1995) The C. elegans ksr-1 gene encodes a novel raf-related kinase involved in Ras-mediated signal transduction. Cell 83(6):889-901

50. Denouel-Galy A, Douville EM, Warne PH, Papin C, Laugier D, Calothy G, Downward J, Eychène A (1998) Murine Ksr interacts with MEK and inhibits Ras-induced transformation. Curr Biol CB 8(1):46-55

51. Yu W, Fantl WJ, Harrowe G, Williams LT (1998) Regulation of the MAP kinase pathway by mammalian Ksr through direct interaction with MEK and ERK. Curr Biol CB 8(1):56-64

52. Müller J, Ory S, Copeland T, Piwnica-Worms H, Morrison DK (2001) C-TAK1 regulates Ras signaling by phosphorylating the MAPK scaffold, KSR1. Mol Cell 8(5):983-993

53. Müller J, Ritt DA, Copeland TD, Morrison DK (2003) Functional analysis of C-TAK1 substrate binding and identification of PKP2 as a new C-TAK1 substrate. EMBO J 22(17):4431-4442

54. Volle DJ, Fulton JA, Chaika OV, McDermott K, Huang H, Steinke LA, Lewis RE (1999) Phosphorylation of the kinase suppressor of Ras by associated kinases $\dagger$. Biochemistry 38(16):5130-5137

55. Cacace AM, Michaud NR, Therrien M, Mathes K, Copeland T, Rubin GM, Morrison DK (1999) Identification of constitutive and Ras-inducible phosphorylation sites of KSR: implications for 14-3-3 binding, mitogen-activated protein kinase binding, and KSR overexpression. Mol Cell Biol 19(1):229-240

56. Canal F, Palygin O, Pankratov Y, Corrêa SAL, Müller J (2011) Compartmentalization of the MAPK scaffold protein KSR1 modulates synaptic plasticity in hippocampal neurons. FASEB J 25(7):2362-2372
57. McKay MM, Ritt DA, Morrison DK (2009) Signaling dynamics of the KSR1 scaffold complex. Proc Natl Acad Sci 106(27):11022-11027

58. Müller J, Cacace AM, Lyons WE, McGill CB, Morrison DK (2000) Identification of B-KSR1, a novel brain-specific isoform of KSR1 that functions in neuronal signaling. Mol Cell Biol 20(15):5529-5539

59. Shalin SC, Hernandez CM, Dougherty MK, Morrison DK, Sweatt JD (2006) Kinase suppressor of Ras1 compartmentalizes hippocampal signal transduction and subserves synaptic plasticity and memory formation. Neuron 50(5):765-779

60. Keyse SM (2000) Protein phosphatases and the regulation of mitogen-activated protein kinase signalling. Curr Opin Cell Biol 12(2): 186-192

61. Caunt CJ, Keyse SM (2013) Dual-specificity MAP kinase phosphatases (MKPs). FEBS J 280(2):489-504

62. Huang CY, Tan TH (2012) DUSPs, to MAP kinases and beyond. Cell Biosci 2(1):24

63. Ekerot M, Stavridis MP, Delavaine L, Mitchell MP, Staples C, Owens DM, Keenan ID, Dickinson RJ, Storey KG, Keyse SM (2008) Negative-feedback regulation of FGF signalling by DUSP6/MKP-3 is driven by ERK1/2 and mediated by Ets factor binding to a conserved site within the DUSP6/MKP-3 gene promoter. Biochem J 412(2):287-298

64. Zhang Z, Kobayashi S, Borczuk AC, Leidner RS, LaFramboise T, Levine AD, Halmos B (2010) Dual specificity phosphatase 6 (DUSP6) is an ETS-regulated negative feedback mediator of oncogenic ERK signaling in lung cancer cells. Carcinogenesis 31(4):577-586

65. Karlsson M, Mathers J, Dickinson RJ, Mandl M, Keyse SM (2004) Both nuclear-cytoplasmic shuttling of the dual specificity phosphatase MKP-3 and its ability to anchor MAP kinase in the cytoplasm are mediated by a conserved nuclear export signal. J Biol Chem 279(40):41882-41891

66. Mandl M, Slack DN, Keyse SM (2005) Specific inactivation and nuclear anchoring of extracellular signal-regulated kinase 2 by the inducible dual-specificity protein phosphatase DUSP5. Mol Cell Biol 25(5):1830-1845

67. Guy GR, Jackson RA, Yusoff P, Chow SY (2009) Sprouty proteins: modified modulators, matchmakers or missing links? J Endocrinol 203(2):191-202

68. Casci T, Vinós J, Freeman M (1999) Sprouty, an intracellular inhibitor of Ras signaling. Cell 96(5):655-665

69. Hacohen N, Kramer S, Sutherland D, Hiromi Y, Krasnow MA (1998) Sprouty encodes a novel antagonist of FGF signaling that patterns apical branching of the drosophila airways. Cell 92(2):253-263

70. Kramer S, Okabe M, Hacohen N, Krasnow MA, Hiromi Y (1999) Sprouty: a common antagonist of FGF and EGF signaling pathways in Drosophila. Development 126(11):2515-2525

71. Ozaki K, Kadomoto R, Asato K, Tanimura S, Itoh N, Kohno M (2001) ERK pathway positively regulates the expression of sprouty genes. Biochem Biophys Res Commun 285(5):1084-1088

72. Panagiotaki N, Dajas-Bailador F, Amaya E, Papalopulu N, Dorey K (2010) Characterisation of a new regulator of BDNF signalling, Sprouty3, involved in axonal morphogenesis in vivo. Development 137(23):4005-4015

73. Haimov-Kochman R, Ravhon A, Prus D, Greenfield C, FinciYeheskel Z, S Goldman-Wohl D, Natanson-Yaron S, Reich R, Yagel S, Hurwitz A (2005) Expression and regulation of Sprouty- 2 in the granulosa-lutein cells of the corpus luteum. Mol Hum Reprod 11(8):537-542

74. Yang X, Webster JB, Kovalenko D, Nadeau RJ, Zubanova O, Chen PY, Friesel R (2006) Sprouty genes are expressed in osteoblasts and inhibit fibroblast growth factor-mediated osteoblast responses. Calcif Tissue Int 78(4):233-240 
75. Sylvestersen KB, Herrera PL, Serup P, Rescan C (2011) Fgf9 signalling stimulates Spred and Sprouty expression in embryonic mouse pancreas mesenchyme. Gene Expr Patterns 11(1-2):105-111

76. Jiang ZL, Ripamonte P, Buratini J, Portela VM, Price CA (2011) Fibroblast growth factor-2 regulation of sprouty and NR4A genes in bovine ovarian granulosa cells. J Cell Physiol 226(7):1820-1827

77. Mason JM, Morrison DJ, Albert Basson M, Licht JD (2006) Sprouty proteins: multifaceted negative-feedback regulators of receptor tyrosine kinase signaling. Trends Cell Biol 16(1):45-54

78. Hanafusa H, Torii S, Yasunaga T, Nishida E (2002) Sprouty1 and Sprouty2 provide a control mechanism for the Ras/MAPK signalling pathway. Nat Cell Biol 4(11):850-858

79. Yusoff P, Lao D-H, Ong SH, Wong ESM, Lim J, Lo TL, Leong HF, Fong CW, Guy GR (2002) Sprouty2 inhibits the Ras/MAP kinase pathway by inhibiting the activation of Raf. J Biol Chem 277(5):3195-3201

80. Sasaki A, Taketomi T, Kato R, Saeki K, Nonami A, Sasaki M, Kuriyama M, Saito N, Shibuya M, Yoshimura A (2003) Mammalian Sprouty4 suppresses Ras-independent ERK activation by binding to Raf1. Nat Cell Biol 5(5):427-432

81. Masoumi-Moghaddam S, Amini A, Morris DL (2014) The developing story of Sprouty and cancer. Cancer Metastasis Rev 33(2-3):695-720

82. Traverse S, Gomez N, Paterson H, Marshall C, Cohen P (1992) Sustained activation of the mitogen-activated protein (MAP) kinase cascade may be required for differentiation of PC12 cells. Comparison of the effects of nerve growth factor and epidermal growth factor. Biochem J 288:351-355

83. Brightman FA, Fell DA (2000) Differential feedback regulation of the MAPK cascade underlies the quantitative differences in EGF and NGF signalling in PC12 cells. FEBS Lett 482(3):169-174

84. Santos SD, Verveer PJ, Bastiaens PI (2007) Growth factor-induced MAPK network topology shapes Erk response determining PC-12 cell fate. Nat Cell Biol 9(3):324-330

85. Kortum RL, Costanzo DL, Haferbier J, Schreiner SJ, Razidlo GL, Wu MH, Volle DJ, Mori T, Sakaue H, Chaika NV, Chaika OV, Lewis RE (2005) The molecular scaffold kinase suppressor of Ras 1 (KSR1) regulates adipogenesis. Mol Cell Biol 25(17):7592-7604

86. Kortum RL, Lewis RE (2004) The molecular scaffold KSR1 regulates the proliferative and oncogenic potential of cells. Mol Cell Biol 24(10):4407-4416

87. Sturm OE, Orton R, Grindlay J, Birtwistle M, Vyshemirsky V, Gilbert D, Calder M, Pitt A, Kholodenko B, Kolch W (2010) The mammalian MAPK/ERK pathway exhibits properties of a negative feedback amplifier. Sci Signal 3(153):ra90

88. Fritsche-Guenther R, Witzel F, Sieber A, Herr R, Schmidt N, Braun S, Brummer T, Sers C, Blüthgen N (2011) Strong negative feedback from Erk to Raf confers robustness to MAPK signalling. Mol Syst Biol 7(1):489

89. Thomas GM, Huganir RL (2004) MAPK cascade signalling and synaptic plasticity. Nat Rev Neurosci 5(3):173-183

90. Davies H, Bignell GR, Cox C, Stephens P, Edkins S, Clegg S, Teague J, Woffendin H, Garnett MJ, Bottomley W, Davis N, Dicks E, Ewing R, Floyd Y, Gray K, Hall S, Hawes R, Hughes J, Kosmidou V, Menzies A, Mould C, Parker A, Stevens C, Watt S, Hooper S, Wilson R, Jayatilake H, Gusterson BA, Cooper C, Shipley J, Hargrave D, Pritchard-Jones K, Maitland N, Chenevix-Trench G, Riggins GJ, Bigner DD, Palmieri G, Cossu A, Flanagan A, Nicholson A, Ho JWC, Leung SY, Yuen ST, Weber BL, Seigler HF, Darrow TL, Paterson H, Marais R, Marshall CJ, Wooster R, Stratton MR, Futreal PA (2002) Mutations of the BRAF gene in human cancer. Nature 417(6892):949-954
91. Gorden A, Osman I, Gai W, He D, Huang W, Davidson A, Houghton AN, Busam K, Polsky D (2003) Analysis of BRAF and N-RAS mutations in metastatic melanoma tissues. Cancer Res 63(14):3955-3957

92. Ross JS, Fletcher JA (1999) The HER-2/neu oncogene: prognostic factor, predictive factor and target for therapy. Semin Cancer Biol 9(2):125-138

93. Pao W, Miller V, Zakowski M, Doherty J, Politi K, Sarkaria I, Singh B, Heelan R, Rusch V, Fulton L, Mardis E, Kupfer D, Wilson R, Kris M, Varmus H (2004) EGF receptor gene mutations are common in lung cancers from "never smokers" and are associated with sensitivity of tumors to gefitinib and erlotinib. Proc Natl Acad Sci USA 101(36):13306-13311

94. Mason CS, Springer CJ, Cooper RG, Superti-Furga G, Marshall CJ, Marais R (1999) Serine and tyrosine phosphorylations cooperate in Raf-1, but not B-Raf activation. EMBO $J$ 18(8):2137-2148

95. Solit DB, Garraway LA, Pratilas CA, Sawai A, Getz G, Basso A, Ye Q, Lobo JM, She Y, Osman I, Golub TR, Sebolt-Leopold J, Sellers WR, Rosen N (2006) BRAF mutation predicts sensitivity to MEK inhibition. Nature 439(7074):358-362

96. Garnett MJ, Rana S, Paterson H, Barford D, Marais R (2005) Wild-type and mutant B-RAF activate C-RAF through distinct mechanisms involving heterodimerization. Mol Cell 20(6):963-969

97. Rushworth LK, Hindley AD, O’Neill E, Kolch W (2006) Regulation and role of Raf-1/B-Raf heterodimerization. Mol Cell Biol 26(6):2262-2272

98. Heidorn SJ, Milagre C, Whittaker S, Nourry A, Niculescu-Duvas I, Dhomen N, Hussain J, Reis-Filho JS, Springer CJ, Pritchard C, Marais R (2010) Kinase-dead BRAF and oncogenic RAS cooperate to drive tumor progression through CRAF. Cell 140(2):209-221

99. Poulikakos PI, Zhang C, Bollag G, Shokat KM, Rosen N (2010) RAF inhibitors transactivate RAF dimers and ERK signalling in cells with wild-type BRAF. Nature 464(7287):427-430

100. Pratilas CA, Taylor BS, Ye Q, Viale A, Sander C, Solit DB, Rosen N (2009) V600EBRAF is associated with disabled feedback inhibition of RAF-MEK signaling and elevated transcriptional output of the pathway. Proc Natl Acad Sci 106(11):4519-4524

101. Dultz LA, Dhar S, Ogilvie JB, Heller KS, Bar-Sagi D, Patel KN (2013) Clinical and therapeutic implications of Sprouty2 feedback dysregulation in BRAF V600E-mutation-positive papillary thyroid cancer. Surgery 154(6):1239-1245

102. Lito P, Pratilas Christine A, Joseph Eric W, Tadi M, Halilovic E, Zubrowski M, Huang A, Wong Wai L, Callahan Margaret K, Merghoub T, Wolchok Jedd D, de Stanchina E, Chandarlapaty S, Poulikakos Poulikos I, Fagin James A, Rosen N (2012) Relief of profound feedback inhibition of mitogenic signaling by RAF inhibitors attenuates their activity in BRAFV600E melanomas. Cancer Cell 22(5):668-682

103. Yao Z, Torres NM, Tao A, Gao YJ, Luo LS, Li Q, de Stanchina E, Abdel-Wahab O, Solit DB, Poulikakos PI, Rosen N (2015) BRAF mutants evade ERK-dependent feedback by different mechanisms that determine their sensitivity to pharmacologic inhibition. Cancer Cell 28(3):370-383

104. Woods D, Parry D, Cherwinski H, Bosch E, Lees E, McMahon M (1997) Raf-induced proliferation or cell cycle arrest is determined by the level of Raf activity with arrest mediated by p21Cip1. Mol Cell Biol 17(9):5598-5611

105. Zhu J, Woods D, McMahon M, Bishop JM (1998) Senescence of human fibroblasts induced by oncogenic Raf. Genes Dev 12(19):2997-3007

106. Leboeuf R, Baumgartner JE, Benezra M, Malaguarnera R, Solit D, Pratilas CA, Rosen N, Knauf JA, Fagin JA (2008) 
BRAFV600E mutation is associated with preferential sensitivity to mitogen-activated protein kinase kinase inhibition in thyroid cancer cell lines. J Clin Endocrinol Metab 93(6):2194-2201

107. Pratilas CA, Hanrahan AJ, Halilovic E, Persaud Y, Soh J, Chitale D, Shigematsu H, Yamamoto H, Sawai A, Janakiraman M, Taylor BS, Pao W, Toyooka S, Ladanyi M, Gazdar A, Rosen N, Solit DB (2008) Genetic predictors of MEK dependence in nonsmall cell lung cancer. Cancer Res 68(22):9375-9383

108. Flaherty KT, Puzanov I, Kim KB, Ribas A, McArthur GA, Sosman JA, O'Dwyer PJ, Lee RJ, Grippo JF, Nolop K, Chapman PB (2010) Inhibition of mutated, activated BRAF in metastatic melanoma. N Engl J Med 363(9):809-819

109. Ascierto PA, Minor D, Ribas A, Lebbe C, O’Hagan A, Arya N, Guckert M, Schadendorf D, Kefford RF, Grob J-J, Hamid O, Amaravadi R, Simeone E, Wilhelm T, Kim KB, Long GV, Martin A-M, Mazumdar J, Goodman VL, Trefzer U (2013) Phase II trial (BREAK-2) of the BRAF inhibitor dabrafenib (GSK2118436) in patients with metastatic melanoma. J Clin Oncol 31(26):3205-3211

110. Ravnan MC, Matalka MS (2012) Vemurafenib in patients with BRAF V600E mutation-positive advanced melanoma. Clin Ther 34(7):1474-1486

111. Robert C, Arnault JP, Mateus C (2011) RAF inhibition and induction of cutaneous squamous cell carcinoma. Curr Opin Oncol 23(2):177-182

112. Poulikakos PI, Solit DB (2011) Resistance to MEK inhibitors: should we co-target upstream? Sci Signal 4(166):pe16

113. Lito P, Rosen N, Solit DB (2013) Tumor adaptation and resistance to RAF inhibitors. Nat Med 19(11):1401-1409

114. Little AS, Balmanno K, Sale MJ, Newman S, Dry JR, Hampson M, Edwards PA, Smith PD, Cook SJ (2011) Amplification of the driving oncogene, KRAS or BRAF, underpins acquired resistance to MEK1/2 inhibitors in colorectal cancer cells. Sci Signal 4(166):ra17

115. Maertens O, Johnson B, Hollstein P, Frederick DT, Cooper ZA, Messiaen L, Bronson RT, McMahon M, Granter S, Flaherty K, Wargo JA, Marais R, Cichowski K (2013) Elucidating distinct roles for NF1 in melanomagenesis. Cancer Discov 3(3):338-349

116. Nazarian R, Shi H, Wang Q, Kong X, Koya RC, Lee H, Chen Z, Lee M-K, Attar N, Sazegar H, Chodon T, Nelson SF, McArthur G, Sosman JA, Ribas A, Lo RS (2010) Melanomas acquire resistance to B-RAF(V600E) inhibition by RTK or N-RAS upregulation. Nature 468(7326):973-977

117. Nissan MH, Pratilas CA, Jones AM, Ramirez R, Won H, Liu C, Tiwari S, Kong L, Hanrahan AJ, Yao Z, Merghoub T, Ribas A, Chapman PB, Yaeger R, Taylor BS, Schultz N, Berger MF, Rosen N, Solit DB (2014) Loss of NF1 in cutaneous melanoma is associated with RAS activation and MEK dependence. Cancer Res 74(8):2340-2350

118. Sun C, Wang L, Huang S, Heynen GJ, Prahallad A, Robert C, Haanen J, Blank C, Wesseling J, Willems SM, Zecchin D, Hobor S, Bajpe PK, Lieftink C, Mateus C, Vagner S, Grernrum W, Hofland I, Schlicker A, Wessels LF, Beijersbergen RL, Bardelli A, Di Nicolantonio F, Eggermont AM, Bernards R (2014) Reversible and adaptive resistance to BRAF(V600E) inhibition in melanoma. Nature 508(7494):118-122

119. Whittaker SR, Theurillat J-P, Van Allen E, Wagle N, Hsiao J, Cowley GS, Schadendorf D, Root DE, Garraway LA (2013) A genome-scale RNA interference screen implicates NF1 loss in resistance to RAF inhibition. Cancer Discov 3(3):350-362

120. Yadav V, Zhang X, Liu J, Estrem S, Li S, Gong X-Q, Buchanan S, Henry JR, Starling JJ, Peng S-B (2012) Reactivation of mitogen-activated protein kinase (MAPK) pathway by FGF receptor 3 (FGFR3)/Ras mediates resistance to vemurafenib in human B-RAF V600E mutant melanoma. J Biol Chem 287(33):28087-28098

121. Montagut C, Sharma SV, Shioda T, McDermott U, Ulman M, Ulkus LE, Dias-Santagata D, Stubbs H, Lee DY, Singh A, Drew L, Haber DA, Settleman J (2008) Elevated CRAF as a potential mechanism of acquired resistance to BRAF inhibition in melanoma. Cancer Res 68(12):4853-4861

122. Shi H, Moriceau G, Kong X, Lee M-K, Lee H, Koya RC, Ng C, Chodon T, Scolyer RA, Dahlman KB, Sosman JA, Kefford RF, Long GV, Nelson SF, Ribas A, Lo RS (2012) Melanoma wholeexome sequencing identifies V600EB-RAF amplification-mediated acquired B-RAF inhibitor resistance. Nat Commun 3:724

123. Kopetz S, Desai J, Chan E, Hecht JR, O'Dwyer PJ, Maru D, Morris V, Janku F, Dasari A, Chung W, Issa JP, Gibbs P, James B, Powis G, Nolop KB, Bhattacharya S, Saltz L (2015) Phase II pilot study of vemurafenib in patients with metastatic BRAFmutated colorectal cancer. J Clin Oncol 33(34):4032-4038

124. Bollag G, Hirth P, Tsai J, Zhang JZ, Ibrahim PN, Cho HN, Spevak W, Zhang C, Zhang Y, Habets G, Burton E, Wong B, Tsang G, West BL, Powell B, Shellooe R, Marimuthu A, Nguyen H, Zhang KYJ, Artis DR, Schlessinger J, Su F, Higgins B, Iyer R, D’ Andrea K, Koehler A, Stumm M, Lin PS, Lee RJ, Grippo J, Puzanov I, Kim KB, Ribas A, McArthur GA, Sosman JA, Chapman PB, Flaherty KT, Xu XW, Nathanson KL, Nolop K (2010) Clinical efficacy of a RAF inhibitor needs broad target blockade in BRAFmutant melanoma. Nature 467(7315):596-599

125. Goldinger SM, Zimmer L, Schulz C, Ugurel S, Hoeller C, Kaehler KC, Schadendorf D, Hassel JC, Becker J, Hauschild A, Dummer R (2014) Upstream mitogen-activated protein kinase (MAPK) pathway inhibition: MEK inhibitor followed by a BRAF inhibitor in advanced melanoma patients. Eur J Cancer (Oxford, England: 1990) 50(2):406-410

126. Flaherty KT, Infante JR, Daud A, Gonzalez R, Kefford RF, Sosman J, Hamid O, Schuchter L, Cebon J, Ibrahim N, Kudchadkar R, Burris HA, Falchook G, Algazi A, Lewis K, Long GV, Puzanov I, Lebowitz P, Singh A, Little S, Sun P, Allred A, Ouellet D, Kim KB, Patel K, Weber J (2012) Combined BRAF and MEK inhibition in melanoma with BRAF V600 mutations. N Engl J Med 367(18):1694-1703

127. Peng SB, Henry JR, Kaufman MD, Lu WP, Smith BD, Vogeti S, Rutkoski TJ, Wise S, Chun L, Zhang Y, Van Horn RD, Yin T, Zhang X, Yadav V, Chen SH, Gong X, Ma X, Webster Y, Buchanan S, Mochalkin I, Huber L, Kays L, Donoho GP, Walgren J, McCann D, Patel P, Conti I, Plowman GD, Starling JJ, Flynn DL (2015) Inhibition of RAF isoforms and active dimers by LY3009120 leads to anti-tumor activities in RAS or BRAF mutant cancers. Cancer Cell 28(3):384-398

128. Villanueva J, Vultur A, Lee JT, Somasundaram R, FukunagaKalabis M, Cipolla AK, Wubbenhorst B, Xu X, Gimotty PA, Kee D, Santiago-Walker AE, Letrero R, D'Andrea K, Pushparajan A, Hayden JE, Brown KD, Laquerre S, McArthur GA, Sosman JA, Nathanson KL, Herlyn M (2010) Acquired resistance to BRAF inhibitors mediated by a RAF kinase switch in melanoma can be overcome by cotargeting MEK and IGF-1R/ PI3K. Cancer Cell 18(6):683-695

129. Atefi M, von Euw E, Attar N, Ng C, Chu C, Guo D, Nazarian R, Chmielowski B, Glaspy JA, Comin-Anduix B, Mischel PS, Lo RS, Ribas A (2011) Reversing melanoma cross-resistance to BRAF and MEK inhibitors by co-targeting the AKT/mTOR pathway. PLoS One 6(12):e28973

130. Shi H, Kong X, Ribas A, Lo RS (2011) Combinatorial treatments that overcome PDGFR $\beta$-driven resistance of melanoma cells to V600EB-RAF inhibition. Cancer Res 71(15):5067-5074

131. Yaeger R, Cercek A, O'Reilly EM, Reidy DL, Kemeny N, Wolinsky T, Capanu M, Gollub MJ, Rosen N, Berger MF, Lacouture ME, Vakiani E, Saltz LB (2015) Pilot trial of combined 
BRAF and EGFR inhibition in BRAF-mutant metastatic colorectal cancer patients. Clin Cancer Res 21(6):1313-1320

132. Mao M, Tian F, Mariadason JM, Tsao CC, Lemos R Jr, Dayyani F, Gopal YN, Jiang ZQ, Wistuba II, Tang XM, Bornman WG, Bollag G, Mills GB, Powis G, Desai J, Gallick GE, Davies MA, Kopetz S (2013) Resistance to BRAF inhibition in BRAF-mutant colon cancer can be overcome with PI3K inhibition or demethylating agents. Clin Cancer Res 19(3):657-667
133. Fattore L, Marra E, Pisanu M, Noto A, de Vitis C, Belleudi F, Aurisicchio L, Mancini R, Torrisi M, Ascierto P, Ciliberto G (2013) Activation of an early feedback survival loop involving phospho-ErbB3 is a general response of melanoma cells to RAF/ MEK inhibition and is abrogated by anti-ErbB3 antibodies. J Transl Med 11(1):180 